\title{
Diagnostic Accuracy of Diffusion Weighted Imaging in Evaluation of High and Low Grade Pediatric Brain Tumors
}

\author{
SAHAR M. ABD EL-SALAM, M.D.* and OMNIA MOKHTAR, M.D.** \\ The Department of Radiology, Faculty of Medicine, Beni-Suef University* and National Cancer Institute, Cairo University**
}

\begin{abstract}
Background: Diagnosis and classification of brain tumors at pediatric age group is a challenging issue. MRI with different sequences including conventional MRI, post contrast study and diffusion weighted imaging (DWI) and well as ADC value measurement are considered accurate imaging modality to properly diagnose, classify brain lesions according to their site, extent and biological behaviour.
\end{abstract}

Aim of Study: To evaluate the diagnostic accuracy of DWI in differentiation of high and low grade pediatric brain tumors.

Patients and Method: Pre-operative MRI examination including; conventional MRI, post contrast study and DWI were done for 30 pediatric patients with suspected brain tumors by $\mathrm{CT}$ examination. Lesions evaluation regarding their size, site, signal intensity, pattern of enhancement, appearance at DWI and ADC values were done for all cases.

Results: The sensitivity, specificity, positive predictive value, negative predictive value and accuracy of diffusion weighted imaging were $89 \%, 100 \%, 100 \%, 86 \%$ and $93 \%$ respectively. All high grade tumors showed restricted diffusion. Post contrast MRI examination revealed no significant difference between low and high grade tumors.

Conclusion: Addition of DWI and ADC values measurement to the routine MRI examination of the brain improved the diagnostic accuracy of prediction of pediatric brain tumor histopathological grade.

Key Words: Pediatric brain tumor - DWI-ADC values Tumor grade.

\section{Introduction}

PEDIATRIC brain tumors are considered worldwide problem. They affect about $25 \%$ of the diagnosed pediatric neoplasms. The highest incidence occurs in developing, low and middle income countries. The overall survival of cases varies according to the demographic and clinical factors [1]

Correspondence to: Dr. Sahar M. Abd El-Salam, The Department of Radiology, Faculty of Medicine, Beni-Suef University, Egypt
Magnetic resonance imaging using multiple sequences provides adequate analysis of the morphological and biological features of the brain tumors [2]. Accurate diagnosis of pediatric brain tumors improves patient's outcome and provides better prognosis. Conventional MRI examination provides adequate data about location and extent of the brain tumors. Diffusion weighted magnetic resonance imaging evaluate the Brownian water motion at microscopic level within tissues [3] Addition of diffusion weighted imaging increases the diagnostic accuracy in detection of brain tumor histopathological grades and better lesion characterization [4-6]

Measurement of Apparent Diffusion Coefficient (ADC) value can be used for pre-operative diagnosis and prediction of histopathological grades of brain tumors $[3,6,7]$

Diffusion Weighted Imaging (DWI) can distinguish tumor types and different histologic grades based on their cellular composition; as highly cellular tumors commonly revealed restricted diffusion with lower ADC values. However, overlap between pediatric brain tumor grades and types is great to diagnose lesions with DWI alone [8-10]

The aim of our study was to evaluate the diagnostic accuracy of DWI in differentiation of high and low grade pediatric brain tumors.

\section{Patients and Methods}

Our prospective study was done between January 2017 and May 2018. Thirty patients (18 male and 12 female) at pediatric age group (less than 18 years) with suspected brain tumor by CT examination were included. Cases were referred from Neurosurgery Department to the Radiology Department of our Institution. They were presenting with headache, vomiting, macrocephaly, gait disturbance 
or personality changes. All cases were examined by brain MRI including; conventional MRI, post contrast study, DWI and ADC value measurement. MRI examinations were done before operative treatment and biopsy. Histopathological evaluation of the lesions was done for all cases. Exclusion criteria included patient's age more than 18 years, post traumatic, post-operative cases, impaired renal function and general contraindications to MR imaging as (pacemaker, metallic prostheses, .... etc). Our study was approved by the ethical committee of our institution. Data for patients were collected only after obtaining informed consents.

\section{MR imaging technique:}

Patients were informed to assess the kidney function before MRI examination to avoid renal insult caused by contrast media. MR imaging was performed by using Siemens aera $1.5 \mathrm{~T}$ device using head coil. Patients instructed to lie in supine position and to avoid unnecessary movement. Initially, conventional MRI examination was done. Axial, coronal and Sagittal T1-wieghted non-contrast images with imaging parameters; repetition time $(\mathrm{TR})=550 \mathrm{~ms}$, echo time $(\mathrm{TE})=9 \mathrm{~ms}$, bandwidth $=$ $150 \mathrm{~Hz} / \mathrm{Px}$, Flip angle $=900$, slice thickness of $5 \mathrm{~mm}$, intersection gap $=1-2 \mathrm{~mm}$ and field of view $=23 \mathrm{~cm}$. Axial and sagittal fast spin-echo T2-weighted images; repetition time $(\mathrm{TR})=3870 \mathrm{~ms}$, echo time $(\mathrm{TE})=93 \mathrm{~ms}$, bandwidth $=191 \mathrm{~Hz} / \mathrm{Px}$, flip angle= 1500 , slice thickness of $5 \mathrm{~mm}$, intersection gap= $1-2 \mathrm{~mm}$ and field of view $=23 \mathrm{~cm}$. Axial Fluidattenuated Inversion Recovery (FLAIR) with imaging parameters; repetition time $(\mathrm{TR})=9620 \mathrm{~ms}$, echo time $(\mathrm{TE})=81 \mathrm{~ms}$, bandwidth $=191 \mathrm{~Hz} / \mathrm{Px}$, Flip angle $=1500$, slice thickness of $5 \mathrm{~mm}$, intersection gap $=1-2 \mathrm{~mm}$ and field of view $=23 \mathrm{~cm}$. Post contrast axial, sagittal and coronal $\mathrm{T} 1$ weighted images were done. Then, DW images were obtained in the axial plane multi-section single shot spin echo EPI sequence using; repetition time $(\mathrm{TR})=4500 \mathrm{~ms}$, echo time $(\mathrm{TE})=79 \mathrm{~ms}$, bandwidth $=1132 \mathrm{~Hz} / \mathrm{Px}$, section thickness $=5 \mathrm{~mm}$, intersection gap of 1 $2 \mathrm{~mm}$, field of view $=23 \mathrm{~cm}$. Signals acquired with $b$-values of 0 and $1000 \mathrm{sec} / \mathrm{mm}^{2}$.

\section{Image analysis:}

All MRI examinations of the study were interpreted by two experienced radiologists in consensus (20 and 15 years' experience) who was blind to the results of histopathological findings. Qualitative and quantitative analysis of brain lesions were done. Qualitative analysis included the site, size, shape, signal intensity, pattern of enhancement, extension and mass effect of the lesions. Appearance at DWI whether facilitated or restricted dif- fusion was detected. Quantitative analysis was done by measuring the ADC values.

\section{$A D C$ values:}

ADC maps were automatically generated by the MRI device software. We drew the Region of Interest (ROI) within the brain mass lesion at the most hypointense area ${ }_{-3}$ We measured the ADC values expressed $X 10^{-3}$ to estimate the degree of diffusion.

\section{Histopathologic analysis:}

Surgical management was done for all cases after MRI examination. The histopathological results obtained from surgical intervention were used as the standard reference of our results. Pathological data included tumour site, type, cell of origin and the WHO grade. The tumor site whether supra or infratentorial, extra or intraventricular. The cell of origin including; astrocytic, ependymal, mixed neuronal and glial, choroid plexus or embryonal cells. WHO grades were classified into four grades: G1 and G2 considered low grade malignancy while G3 and G4 as high grade malignancy [11]

\section{Statistical analysis:}

The statistical analysis of our study was done using SPSS Version 22 software programs (SPSS Inc., Chicago, Illinois, USA). We described quantitative data in terms of mean, median and SD, while qualitative data were expressed as frequency and percentages. Comparison between groups using nonparametric Mann Whitney or kruskal Wallis test when data not normally distributed. Diagnostic performance of DWI was calculated using MedCalversion 18.10.2 software in terms of sensitivity, specificity, positive predictive value, negative predictive value and accuracy. The significance of the results was assessed in the form of $p$-value that was differentiated into: Non-significant when $p$ value $>0.05$, significant when $p$-value $\leq 0.05$ and highly significant when $p$-value $\leq 0.01$.

\section{Results}

Our study included 30 patients; 18 male and 12 female patients. They were presenting with headache $(8 / 30)$, macrocephaly $(8 / 30)$, vomiting $(6 / 30)$, gait disturbances $(6 / 30)$ or personality changes $(2 / 30)$. Their ages were ranging from one year to 18 years, mean \pm SD $(6.6 \pm 5.73)$. All cases undergone MRI examinations; including conventional MRI, post contrast study, DWI and measurement of ADC values. Most cases had solitary intracranial lesions except two cases showed multicenteric tumors. 
Contrast enhanced MRI examination showed; intense enhancement in 4/30 (13\%) cases, two of them were low grade and two cases were high grade tumors. Heterogeneous enhancement was detected in 22/30 (73\%) cases; 8 cases had low grade and 14 had high grade lesions. Faint enhancement of the lesions was seen in 4 cases; two cases low and two cases were high grade tumors. Pattern of contrast enhancement was not significant regarding differentiation between low and high grade tumors ( $p$-value $>0.05$ ).

Surgical management was performed for all cases with histopathological evaluation of the brain tumors. According to lesions site; we found supratentorial tumors in $20(67 \%)$ cases; multicenteric glioblastoma $2 / 30$, subependymal giant cell astrocytoma $2 / 30$, anaplastic ependymoma $6 / 30$, high grade astrocytoma $4 / 30$, choroid plexus carcinoma $2 / 30$ and dysmoplastic infantile astrocytoma $4 / 30$. Infratentorial tumors in 10 (33\%) cases; pilocytic astrocytoma $2 / 30$, low grade glioma $2 / 30$, ependymoma $2 / 30$ and medulloblastoma $4 / 30$. WHO grading of our study revealed; 12 cases had low grade tumors (grade 1 and 2) (subependymal giant cell astrocytoma, pilocytic astrocytoma, low grade glioma, ependymoma and desmoplastic infantile astrocytoma). Eighteen cases showed high grade malignant tumors (grade 3 and 4) including; multicentric glioblastoma, anaplastic ependymoma, high grade astrocytoma, choroid plexus carcinoma and medulloblastoma (Table 1).

Diffusion weighted imaging of the brain lesions revealed that; restricted diffusion in 16 cases (all of them were high grade tumors) and facilitated diffusion in 14 cases (12 cases with low grade and 2 high grade tumors). Restricted diffusion appeared hyperintense at DWI and hypointense at ADC maps Figs. (1-3). The results of histopathology were compared to diffusion weighted imaging for assessment of diagnostic performance of DWI in diagnosis of low and high grade brain tumors as shown in (Table 2) considering the pathological findings as the gold standard in our study. The sensitivity, specificity, positive predictive value, negative predictive value and accuracy were $89 \%$, $100 \%, 100 \%, 86 \%$ and $93 \%$ respectively.
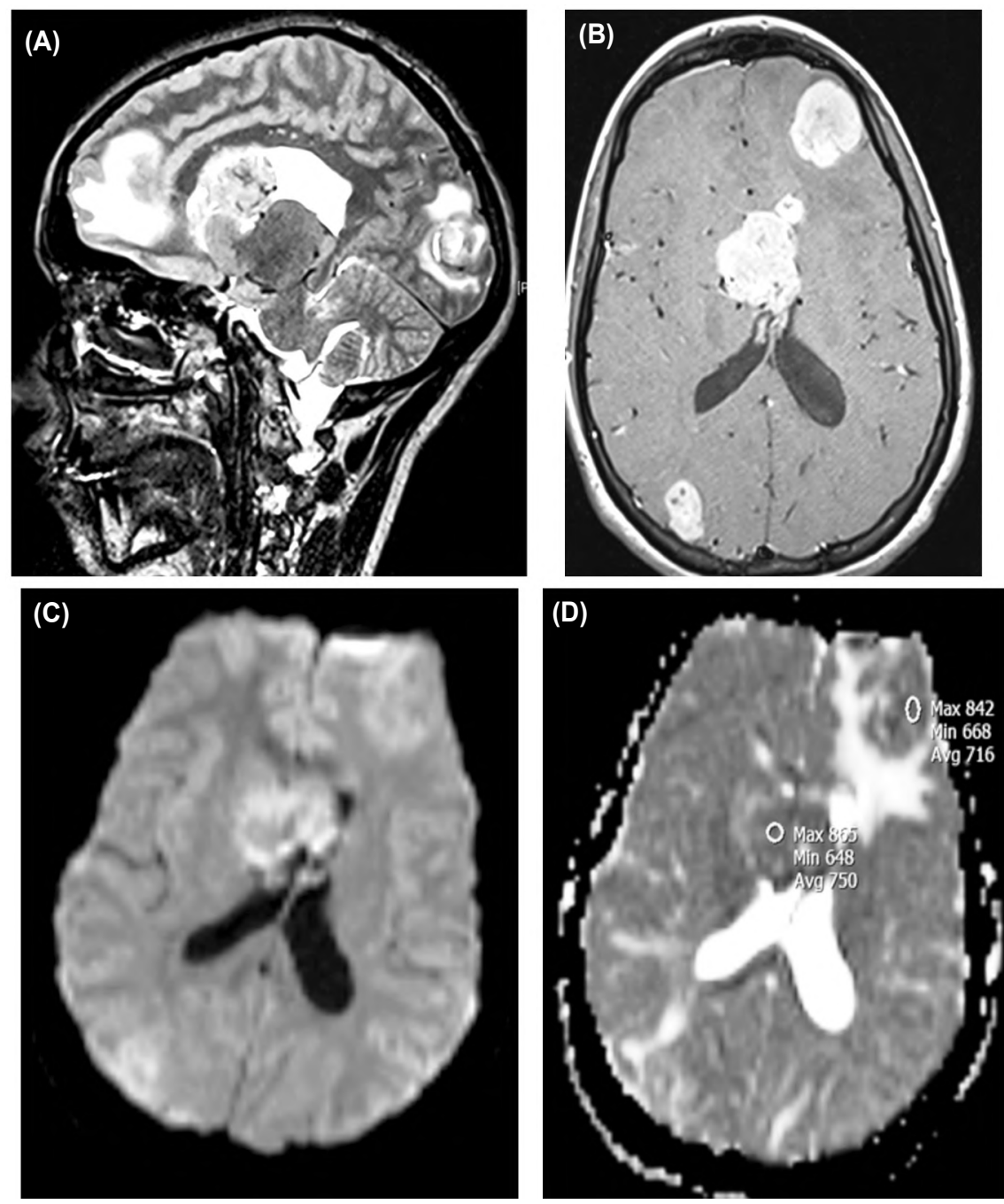

Fig. (1): 18-year-old female patient presented with severe headache. (A) Sagittal T2WI showing mixed signal intensity, (B) Post contrast T1WI, multiple intensely enhanced supratentorial intra axial Space Occupying Lesions (SOL), surrounded by mild to moderate perilesional oedema. (C,D) DWI and ADC value showing restricted diffu $\underline{-}_{\overline{3}}$ sion, reduced $\mathrm{ADC}$ value $(0.71 \mathrm{X} 10$ $\left.\mathrm{mm}^{2} / \mathrm{sec}\right)$. Pathology, multicentric Glioblastoma Multiforms WHO Grade IV. 

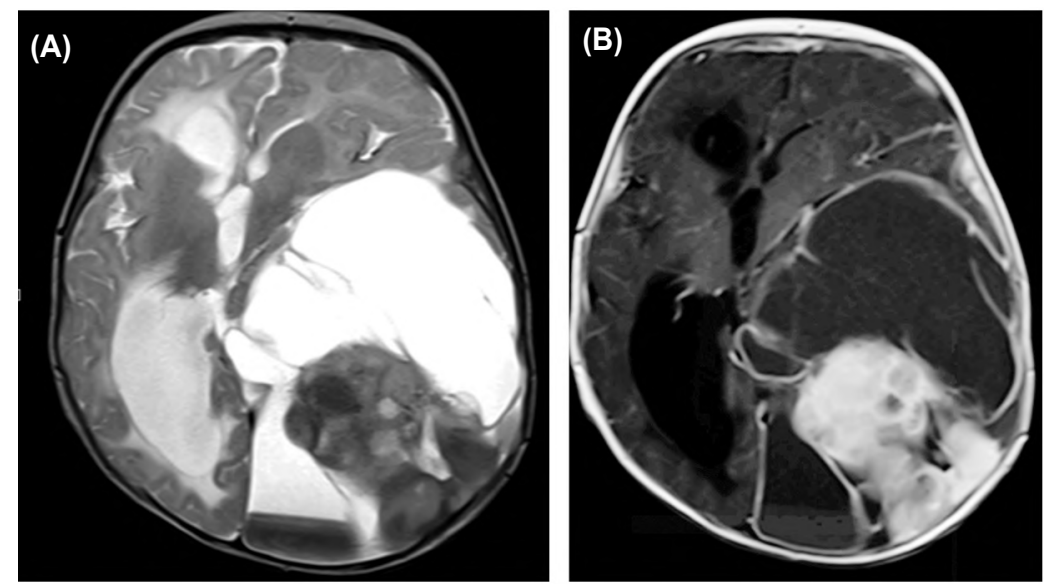

Fig. (2): 1-year old male infant presenting with macrocephaly. (A) Large intraaxial SOL with cystic and solid component of low T2 signal. (B) Heterogeneously enhancing solid
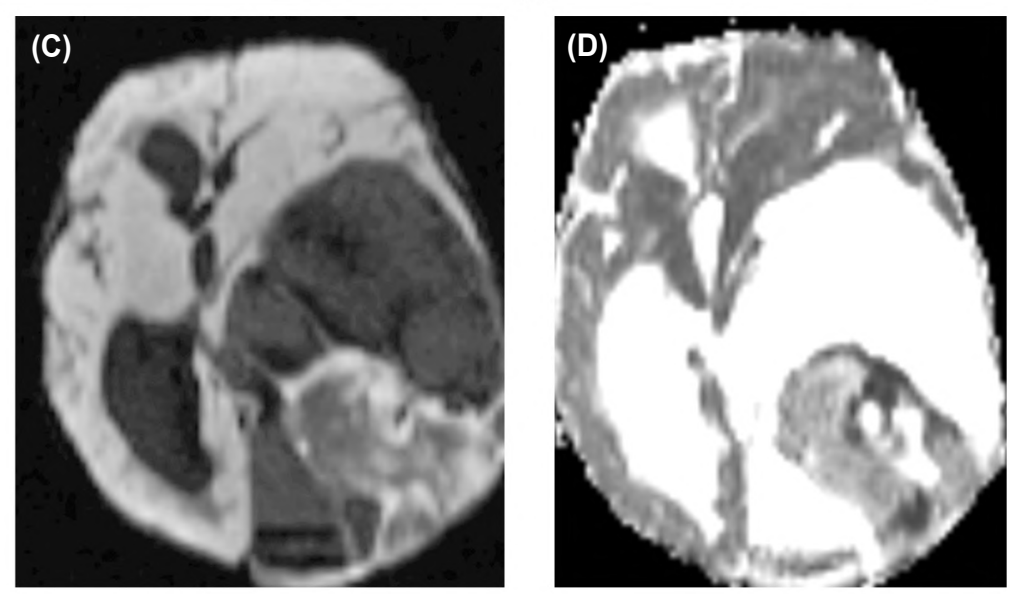
component. (C,D) Facilitated diffusion at $\mathrm{DWI}_{3}$ and elevated $\mathrm{ADC}$ value (1.2 X $10 \mathrm{~mm} / \mathrm{sec})$. Pathology, desmoplastic infantile astrocytoma WHO Grade I.
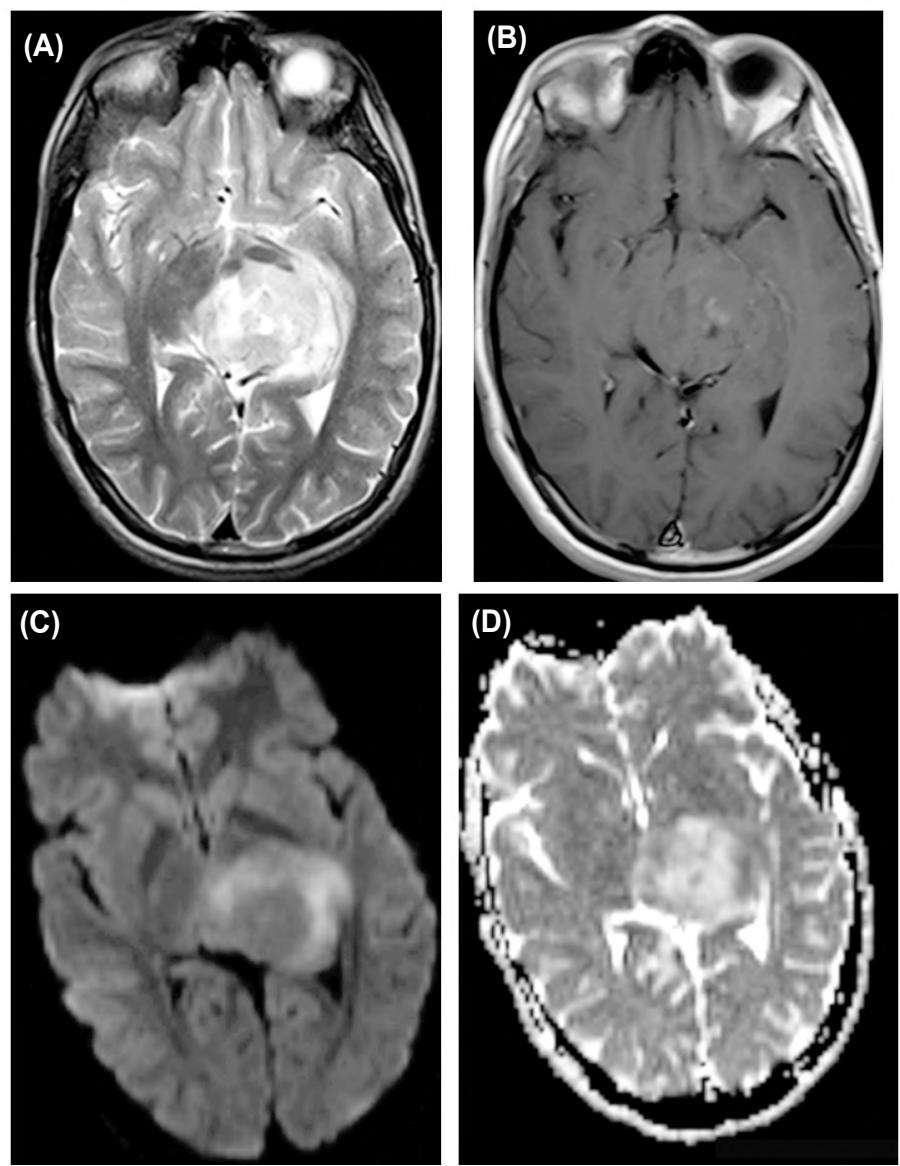

Fig. (3): 14-year-old female patient presented with gait disturbance. (A) Axial T2WI showing left thalamic inhomogeneously hyperintense SOL, (B) Post contrast axial image with faint enhancement of the lesion, (C,D) Facilitated diffusion, ${ }_{2}$ elevated ADC value $(0.92 \times 10 \mathrm{~mm} / \mathrm{sec})$ of the lesion. Pathology high grade astrocytoma, WHO Grade III (false negative case). 
Table (1): Histopathological classification and tumor grades.

\begin{tabular}{llll}
\hline \multicolumn{4}{c}{ Tumor grade No. (\%) } \\
\hline & $\begin{array}{l}\text { Low } \\
\text { grade }\end{array}$ & $\begin{array}{l}\text { High } \\
\text { grade }\end{array}$ & Total \\
\hline Pathology: & & & \\
- Multicentric glioblastoma & $0(0)$ & $2(6.7)$ & $2(6.7)$ \\
- Subependymal giant cell & $2(6.7)$ & $0(0)$ & $2(6.7)$ \\
$\quad$ astrocytoma & & & $6(20)$ \\
- Anaplastic ependymoma & $0(0)$ & $6(20)$ \\
- Pilocytic astrocytoma & $2(6.7)$ & $0(0)$ & $2(6.7)$ \\
- High grade astrocytoma & $0(0)$ & $4(13.3)$ & $4(13.3)$ \\
- Choroid plexus carcinoma & $0(0)$ & $2(6.7)$ & $2(6.7)$ \\
- Low grade glioma & $2(6.7)$ & $0(0)$ & $2(6.7)$ \\
- Ependymoma & $2(6.7)$ & $0(0)$ & $2(6.7)$ \\
- Medulloblastoma & $0(0)$ & $4(13.3)$ & $4(13.3)$ \\
- Dysmoplastic infantile & $4(13.3)$ & $0(0)$ & $4(13.3)$ \\
$\quad$ astrocytoma & & & \\
\hline Total & $12(40)$ & $18(60)$ & $30(100)$ \\
\hline
\end{tabular}

The ADC values were calculated for each grade of tumors as shown in (Table 3 ). We found that grade 1 and 2 tumors (low grade tumors) had the highest $\mathrm{ADC}_{-3}$ yalues with mean $\pm \operatorname{Std}\left(1.15 \times 10^{-3}\right.$ $\left.\pm 0.053 \times 10^{-3}\right),\left(1.39 \times 10^{-3} \pm 0.47 \times 10^{-3}\right)$. While grade 3 and 4 (high grade tumors) had the lowest ADC values with mean $\pm \operatorname{Std}\left(0.62 \times 10^{-3} \pm 0.25\right.$
$\left.\mathrm{X} 10^{-3}\right),\left(0.66 \times 10^{-3} \pm 0.18 \times 10^{-3}\right)$. There was inverse relation between the tumor grade and mean $\mathrm{ADC}$ values.

Table (2): Diagnostic performance of DWI in diagnosis of high and low grade brain tumors.

\begin{tabular}{lcc}
\hline \multirow{2}{*}{ DWIs findings } & \multicolumn{2}{c}{ Final diagnosis } \\
\cline { 2 - 3 } & $\begin{array}{c}\text { Low grade } \\
\text { tumors (12) }\end{array}$ & $\begin{array}{c}\text { High grade } \\
\text { tumors (18) }\end{array}$ \\
\hline Facilitated diffusion & $12(\mathrm{TN})$ & $2(\mathrm{FN})$ \\
Restricted diffusion & $0(\mathrm{FP})$ & $16(\mathrm{TP})$ \\
Sensitivity & $89 \%(65-99 \%)$ \\
Specificity & $100 \%(73.5-100 \%)$ \\
PPV & $100 \%$ & \\
NPV & $86 \%(62-96 \%)$ \\
Accuracy & $93 \%(78-99 \%)$ \\
\hline
\end{tabular}

Nonparametric, Kruskal Wallis test was done to detect the statistical difference between ADC values of different tumor grades (data were not normally distributed), it illustrated that there was a statistically significant difference between grade 1 and 3 , grade 1 and 4 , grade 2 and 3 , grade 2 and 4 with $p$-values were $0.005,0.001,0.038$ and 0.02 respectively. No statistically significant difference was detected between grade 1 and grade 2 as well as grade 3 and grade 4 ( $p$-values were $>0.05$ ).

Table (3): Represents the ADC values mean, median, range, Std, minimum and maximum levels at different tumor histologic grades.

\begin{tabular}{|c|c|c|c|c|c|c|c|}
\hline & $\mathrm{N}$ & Mean & Range & Median & Std. Deviation & Minimum & Maximum \\
\hline Grade 1 & 8 & $1.15 \times 10_{-3}^{-3}$ & $0.1 \times 10_{-3}^{-3}$ & $1.15 \times 10_{-3}^{-3}$ & $0.05 \times 10_{-3}^{-3}$ & $1.1 \times 10^{-3}$ & $1.2 \times 10_{-3}^{-3}$ \\
\hline Grade 2 & 4 & $1.39 \times 10^{-3}$ & $0.82 \times 10^{-3}$ & $1.39 \times 10^{-3}$ & $0.47 \times 10^{-3}$ & $0.98 \times 10_{-3}^{-3}$ & $1.8 \times 10^{-}$ \\
\hline Grade 3 & 8 & $0.62 \times 10_{-3}^{-3}$ & $0.56 \times 10_{3}^{-3}$ & $0.76 \times 10_{-3}^{-3}$ & $0.25 \times 10_{-3}^{-3}$ & $0.24 \times 10_{-3}^{-3}$ & $0.8 \times 10_{-3}^{-3}$ \\
\hline Grade 4 & 10 & $0.66 \times 10^{-3}$ & $0.6 \times 10$ & $0.63 \times 10^{-}$ & $0.18 \times 10^{-}$ & $0.35 \times 10^{-3}$ & $0.92 \times 10$ \\
\hline
\end{tabular}

\section{Discussion}

Pediatric brain tumors are considered the second most common neoplastic lesions at that age group [12]. Management and prognosis differ according to the tumor type, extent and WHO grade [13] Magnetic resonance imaging using multiple sequences provides adequate analysis of the morphological and biological features of the brain tumors [2]. Diffusion weighted imaging can be used to assess tumor cellularity and grading [14]

Raisi-Nafchi et al., [15] reported an indirect relation between ADC value and histopathological grade of the tumors. Increased cellularity in higher grade tumors shows restricted diffusion at Diffusion Weighted Images (DWI), and vice versa $[\mathbf{5 , 1 6 , 1 7 ]}$ So, restricted diffusion can be used to correspond to high grade pediatric brain tumors [18]
The present study revealed restricted diffusion in most of high grade tumors ( $89 \%$ of cases). All cases with low grade tumors showed facilitated diffusion. We reported high specificity and positive predictive value of DWI. So, the presence of restricted diffusion could be considered as predictor of high grade tumors and also almost exclude low grade tumors. Our results agree with previous studies $[4,6,16,19]$; who stated that the presence of restricted diffusion is highly predictive of tumors with high grade.

Studies done by $[4,6,13]$; reported that ADC values could be used in differentiating cell types of brain tumors with similar pathological grades. in our study, we found no statistical significance between cell types and ADC values.

We found that the sensitivity, specificity, PPV, NPV and accuracy of DWI in differentiating 
high from low grade brain tumors were $89 \%$, $100 \%, 100 \%, 86 \%$ and $93 \%$ respectively. These results were similar to that reported by Peter et al., 2006 [20].

Our study included 2 false negative cases and no false positive cases. This signify that the presence of restricted diffusion is a sure sign of malignant lesions. These results also agree with Peter et al., 2006 [20] who reported three false negative and no false positive cases. The presence of facilitated diffusion could occur in $11 \%$ of malignant lesions. So, further assessment of such cases is required to determine tumor grade, evaluation of ADC value, clinical examination of the patient and morphological evaluation of the lesion may support the diagnosis whether towards malignant or benign lesions. Low ADC values most probably supports malignant lesions.

Although, ADC value can be used as predictor of histopathologic grade of the brain tumor [6], there is wide overlap of ADC values without definite cutoff values [10].

Our study included; supratentorial and infratentorial tumors. Intra and extraventricular tumors. Study done by Abdulaziz et al., 2019 [21]. Included extraventricular tumors only. Dolecek et al., 2012; reported that $50 \%$ of intracranial tumors in pediatric patients were found in the posterior fossa [22]. In our study infratentorial tumors were found in $33 \%$ of cases.

\section{Conclusion:}

Addition of DWI and ADC values to the routine MRI examination of the brain improved the diagnostic accuracy of prediction of pediatric brain tumors histopathological grade.

\section{References}

1- AUWARTER E., SHYR D., MA C., ABDEL AZIZ A., MAHER I., EL HADDAD A., IBRAHIM A., EL BELTAGY M., MARCUS K., ZAGHLOUL M. and MANLEY P.: Comparative survival analysis of pediatric central nervous system tumors between Boston and Egypt, NeuroOncology, Volume 20, Issue suppl_2, 22 June, Pages i80, https://doi.org/10.1093/neuonc/noy059.235, 2018.

2- WIENS A.L. and HATTAB E.M.: The pathological spectrum of solid CNS metastases in the pediatric population, J. Neurosurg. Pediatr. 14: 129-135, https://doi.org/10 3171/2014.5.PEDS13526, 2014.

3- BAMMER R.: Basic principles of diffusion-weighted imaging, Eur. J. Radiol., 45: 169-84, 2003.

4- BULAKBASI N., GUVENC I., ONGURU O., ERDOGAN E., TAYFUN C. and UCOZ T.: The added value of the apparent diffusion coefficient calculation to magnetic resonance imaging in the differentiation and grading of malignant brain tumors. J. Comput. Assist Tomogr., 28: 735-46, 2004.

5- WILKE M., EIDENSCHINK A., MULLER-WEIHRICH S. and AUER D.P.: MR diffusion imaging and $1 \mathrm{H}$ spectroscopy in a child with medulloblastoma. A case report. Acta. Radiol., 42: 39-42, 2001.

6- YAMASAKI F., KURISU K., SATOH K., ARITA K., SUGIYAMA K., OHTAKI M., TAKABA J., TOMINAGA A., HANAYA R., YOSHIOKA H., HAMA S., ITO Y., KAJIWARA Y., YAHARA K., SAITO T. and THOHAR M.A.: Apparent diffusion coefficient of human brain tumors at MR imaging. Radiology, 2 (35): 985-91, 2005.

7- YOUNG G.S.: Advanced MRI of adult brain tumors, Neurol. Clin., 25: 947-73, 2007.

8- KAN P., LIU J.K., HEDLUND G., et al.: The role of diffusion-weighted magnetic resonance imaging in pediatric brain tumors. Childs Nerv. Syst., 22: 1435-9, 2006.

9- TZIKA A.A., ZARIFI M.K., GOUMNEROVA L., et al.: Neuroimaging in pediatric brain tumors: Gd-DTPAenhanced, hemodynamic, and diffusion MR imaging compared with MR spectroscopic imaging. AJNR Am. J. Neuroradiol., 23: 322-33, 2002.

10- SCHNEIDER J.F., CONFORT-GOUNY S., VIOLA A., et al.: Multiparametric differentiation of posterior fossa tumors in children using diffusion-weighted imaging and short echo-time 1H-MR spectroscopy. J. Magn. Reson. Imaging, 26: 1390-8, 2007.

11- LOUIS D.N., PERRY A., REIFENBERGER G., VON DEIMLING A., FIGARELLA-BRANGER D., CAVENEE W.K., OHGAKI H., WIESTLER O.D., KLEIHUES P. and ELLISON D.W.: The 2016 World Health Organization classification of tumors of the central nervous system: A summary, Acta. Neuropathol., 131: 803-20, 2016.

12- JONES D.K.: Diffusion MRI: Theory, Methods, and Applications. 1 st ed., Oxford University Press, 2011.

13- GAUVAIN K.M., McKINSTRY R.C., MUKHERJEE P., et al.: Evaluating pediatric brain tumor cellularity with diffusion-tensor imaging. Am. J. Roentgenol., 177: 44954, 2001.

14- MORITANI T., EKHOLM S. and WESTESSON P.: Diffusion-Weighted MR Imaging of the Brain, 1 st ed., Springer-Verlag Berlin Heidelberg, 2005.

15- RAISI-NAFCHI M., FAEGHI F., ZALI A., HAGHIGHATKHAH H. and JALAL-SHOKOUHI J.: Preoperative grading of astrocytic supratentorial brain tumors with diffusion weighted magnetic resonance imaging and apparent diffusion coefficient, Iran. J. Radiol., 13; e30426, 2016.

16- KONO K., INOUE Y., NAKAYAMA K., SHAKUDO M., MORINO M., OHATA K., WAKASA K. and YAMADA R.: The role of diffusion-weighted imaging in patients with brain tumors, Am. J. Neuroradiol. 22: 1081-8, 2001.

17- KRABBE K., GIDEON P., WAGN P., HANSEN U., THOMSEN C. and MADSEN F.: MR diffusion imaging of human intracranial tumours, Neuroradiology, 39: 4839, 1997.

18- KAN P., LIU J.K., HEDLUND G., BROCKMEYER D.L., WALKER M.L. and KESTLE J.R.: The role of diffusionweighted magnetic resonance imaging in pediatric brain tumors, Childs Nerv. Syst., 22: 1435-9, 2006. 
19- KLISCH J., HUSSTEDT H., HENNINGS S., VONVELTHOVENV., PAGENSTECHER A. and SCHUMACHER M.: Supratentorial primitive neuroectodermal tumours: Diffusion-weighted MRI. Neuroradiology, 42: 393-8, 2000.

20- KAN P., LIU J., HEDLUND G., BROCKMEYER D., WALKER M. and KESTLE J.: The role of diffusionweighted magnetic resonance imaging in pediatric brain tumors, Childs Nerv. Syst., 22: 1435-9, 2006.
H.S., AL-SUHAIBANI S.S., AL-AFTAN M.S., ALMEDALLAH D.K., AL-ABDULWAHHAB A.H., AL-HEDAITHY A.A. and AL-JUBRAN S.A.: Can apparent diffusion coefficient values help distinguish between different types of pediatric brain tumors? European Journal of Radiology Open, 6: 49-55, 2019.

22- DOLECEK T.A., PROPP J.M., STROUP N.E. and KRUCHKO C.: CBTRUS statistical report: Primary brain and central nervous system tumors diagnosed in the United States in 2005-2009, Neuro. Oncol., 14: v1-49, 2012.

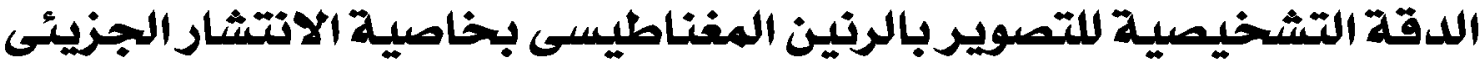

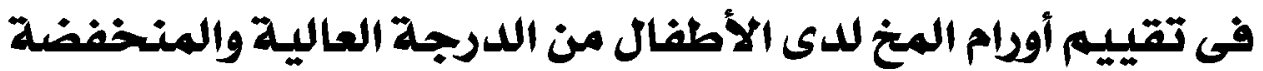

\author{
الخفية: يعتبر تشخيص وتصنيف أودام المغ فى الفئة العمرية للأطفال مشكلة صعبة، التصوير بالرنين المغناطيسى مع تسلسلات مختلفة

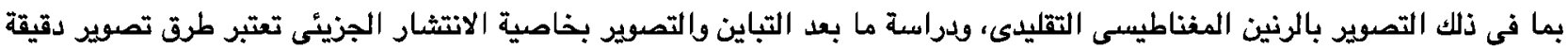

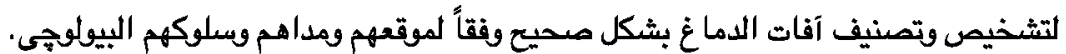 \\ الهدف: تقييم دقة تشخيص التصوير بالرئين المغناطيسى بخاصية الانتشار الجزيئى فى التمايز بين أودام الدماغ الأطفال عالية ومنخفضة \\ الدرجة.

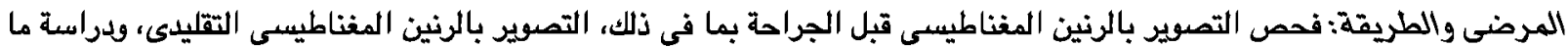

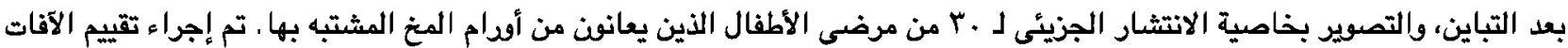

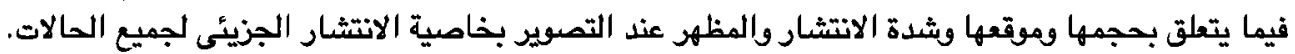

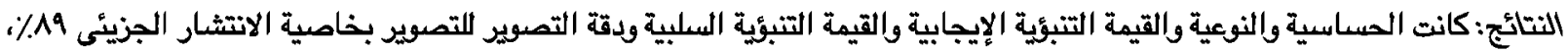

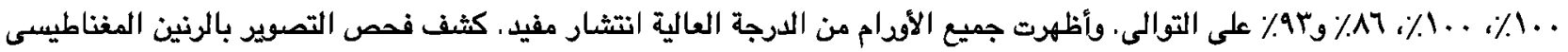 \\ بالصبغة عدم وجود فرق كبير بين الأودام منخفضة وعالئ والية الدرجة. \\ الخلاصة: أدت إضافة التصوير بالرنين المغناطيسى بخاصية الانتثار الجزيئي إلى الفحص الريتينى اللتصوير بالرنين المغناطيسى اللدماغ

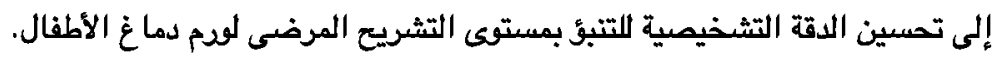

